\title{
Planning and developing medical tourism in megalopolis Shiraz
}

\author{
Masoud Safaeepour ${ }^{\mathrm{a}}$, Majid Goodarzi ${ }^{\mathrm{b}^{*}}$ and Nosrat allah Rostami kondari ${ }^{\mathrm{c}}$
}

\begin{tabular}{l}
${ }^{a}$ Associate Professor of Geography and \\
${ }^{b}$ Assistant Professor of Geography and \\
${ }^{c}$ MA Student of Geography and Urban P \\
\hline C H R O N I C L E \\
\hline Article history: \\
Received March 18, 2014 \\
Accepted 26 November 2014 \\
Available online \\
November 282014 \\
\hline Keywords: \\
Medical Tourism \\
Foreign Tourism \\
Treatment Centers \\
Satisfaction \\
Megalopolis Shiraz
\end{tabular}

\section{Introduction}

Tourism is a geographical activity (Williams, 2009) and today, tourism industry is considered as one of the growing industries in the world (Avdimiotis et al., 2009). Tourism is the largest economic activity in the world (Masoumi, 2008); it is also a major economic factor for countries with limited revenues. In addition, this industry can gain necessary foreign capitals to the economy and result in positive environmental, economic and social consequences for the host country (Gilmore, 2008). In recent years, there has been a growing trend on international tourism market and according to World Tourism Organization, international tourist trips with almost tripled growth will reach 8.6 billion triples worth approximately 2 trillion dollars annually in 2020. Medical tourism is one of the promising sectors in

*Corresponding author.

E-mail addresses: goodarzi5@yahoo.com (M. Goodarzi)

(C) 2015 Growing Science Ltd. All rights reserved.

doi: $10.5267 /$ j.msl.2014.11.013

\begin{abstract}
Medical tourism is an international phenomenon where some tourists travel long to reach treatment-therapeutic services because of high expenses, long waits, lacking in insurance, and applying services and insufficient access to health services in the destination. This industry, now, by making 60 billion dollars annually in international level, has been considered as one the most profitable markets and the number of countries to provide facilities and treatment services for foreign tourists tend to increase. Many countries provide applicable and legal plans for development of this industry. This paper aims at planning and improving medical tourism in megalopolis Shiraz. The dominating approach in the present study is developmental-applied and the method is descriptive, analytical and survey study. To analyze the data and to test the research hypothesis, the linear Pearson correlation and ANOVA were used. The results of the present study have indicated that all quality factors of treatment and tourism services, culture, facilities, medical and tourist equipment and ICT, had positive and direct correlation with developing medical tourism and the factor of price had negative and reverse correlation with it. In other words, the higher the price is, the less the medical tourism development is and vice versa. Also, the ANOVA showed that among medical tourists from various countries regarding satisfaction with the price of treatment and tourist services, the quality of treatment and tourist services, culture, facilities, medical and tourist equipment and ICT, there are significant differences and Kuwaiti tourists were the most satisfied tourists and Afghani ones were the least satisfied.
\end{abstract}


world tourism industry, which has encouraged related firms and countries interested in tourism development to pay more attention to this part of the industry and plan for it. Today, the relationship between economic growth and healthcare development is clearly known. In current approaches, it is not the health sector alone that benefits from economic growth, it can also bring many commercial advantages to countries and in addition to creating new financial resources for infrastructure and technology development, plays essential role in inter-sectorial strategies of sustained development (Amodeo, 2010). Medical tourism market is growing and medical tourists are looking for high quality, cost-effective medical treatments. The number of people who use healthcare services is increasing substantially and exports of such services in the period between 1997 and 2003 has doubled. This increasing trend in the world is ten times faster than foreign tourism revenues and ten times faster than world service exports. Healthcare services accounted for about 0.73 percent of world trading in 2003, 0.38 in 1997, while the share of this market in developing countries was 40 percent (Lautier, 2008; Angelevska-Najdeska \& Rakicevik, 2012). Annually, there are 4 million international patients throughout the world worth around 60 billion dollars (Smith et al., 2009). About 7 billion dollars of this trade is Asia's share. It is assumed that medical tourism comprises 5 percent of the whole world tourism. To sum, this market is vast and developed. This trade is a 60-billion-dollar world trade enjoying a 20-percent annual growth (Horowitz et al, 2007). “...whatever you call it, this is a business activity used in the area of healthcare for the first time in the last 50 years" (Bina, 2007: 48).

According to its planning, at the end of its fourth development plan, Iran has to provide for 30 percent of its medical and health needs by exporting medical goods, medical services and medical tourism. In addition to exports of medical goods and services, revenues from medical tourism can also be effective for countries, particularly Asian countries, who envision progress in their development path (Faramarzi, 2011). These revenues have caused some Asian countries such as Singapore, Thailand and India to extensively advertise their medical services among international patients. However, inexpensiveness of healthcare prices in Iran compared with other countries, reasonable quality and keeping up with latest methods of medicine in the world are among the factors that might help Iranian medical tourism thrive. Shiraz has been traditionally known in Iran as "Dar-ulElm" (City of Knowledge) and a gathering place for well-known scientists and prominent physicians in various historical epochs. Nowadays, considering the presence of Shiraz University of Medical Sciences and efforts made by the management, academic staff and researchers of this university, Shiraz City is considered as before one of the distinguished medical centers in Iran and in the region; ranking as the $2^{\text {nd }}$ best medical science university in the country in this tears further corroborates this claim. The city of Shiraz has many advantages and capacities as regards medical tourism, which have made Shiraz known as the medical tourism heart of the country. Some of the advantage and capacities of Shiraz City regarding medical tourism attraction are: low price of healthcare services, achieving third rank in world in the number of organ transplants (in 2010, it achieved fourth place with 250 transplants; however, having performed more than 310 transplants, it has currently got promoted to the third ranking in the world. In addition to achieving third place in the world in number of organ transplants performed, certain transplant operations in Iran including pancreas and liver transplant are performed only in Shiraz. Since 1988, more than 2360 kidney transplants, since 1993, 1388 liver transplant and since 2006, 98 pancreas transplants have been performed in the organ transplant department of Shiraz's Namazi Hospital which shows Shiraz's enormous potential in the field of organ transplant) (Shiraz University of Medical Sciences' Statistics Center, 2014) and presence of specialist hospitals and construction of new hospitals such as Ibn-e Sina Organ Transplantation Hospital, MRI International Hospital, OstadKhodadoost Eye Hospital, Kosar Heart Center, Ami-al Mo'menin Burning Accidents, etc. With respect to its advantages in medical tourism, Shiraz City has decided to exploit existing opportunities; it has encountered, however, some challenges in using its capabilities in this regard. Due to Shiraz's important medical tourism position in world economy and also the potentials of Shiraz City in this industry, this study has been conducted with the aim of planning and developing medical tourism (with emphasis on foreign tourism) in the city of Shiraz (Delgoshaee et al., 2011; Hinnawi, 2007; Kalshetti \& Pillai, 2008; Keckley \& Underwood, 2009; Monica \& Yu-Feng, 2006; Moshiri \& Fathollahi, 2010). 


\section{Research Hypotheses}

In order to fulfill the objectives introduced, the following hypotheses were formed:

- The medical and tourist service prices are associated with medical tourism development in Shiraz City.

- The quality of medical and tourist services are associated with medical tourism development in Shiraz City.

- Culture is related to medical tourism in Shiraz City.

- Medical and tourist facilities, amenities and equipment are associated with medical tourism development in Shiraz City.

- Information and communications technology are associated with medical tourism development in Shiraz City.

- There are differences between foreign medical tourists in terms of degree of satisfaction (of prices, quality, culture, facilities, amenities and equipment, and information and communications technology).

\section{The Area under Study}

Shiraz, the capital of Fars Province, is located on the longitude of 52 degrees and 32 minutes E and latitude of 29 degrees and 36 minutes $\mathrm{N}$ in the elevation of 1486 meters above the sea level, 919 kilometers off the capital. With an area of $1256 \mathrm{sq.} . \mathrm{km}$, Shiraz is the third city in Iran after Tehran and Mashhad in terms of largeness (Fars Province Planning and Budget Organization, 1391: 1). Shiraz is sisters with four cities in the world: 1. Dushanbe (Tajikistan). 2. Nicosia (Cyprus). 3. Chongqing (China), and Weimar (Germany) (www.eshiraz.ir).

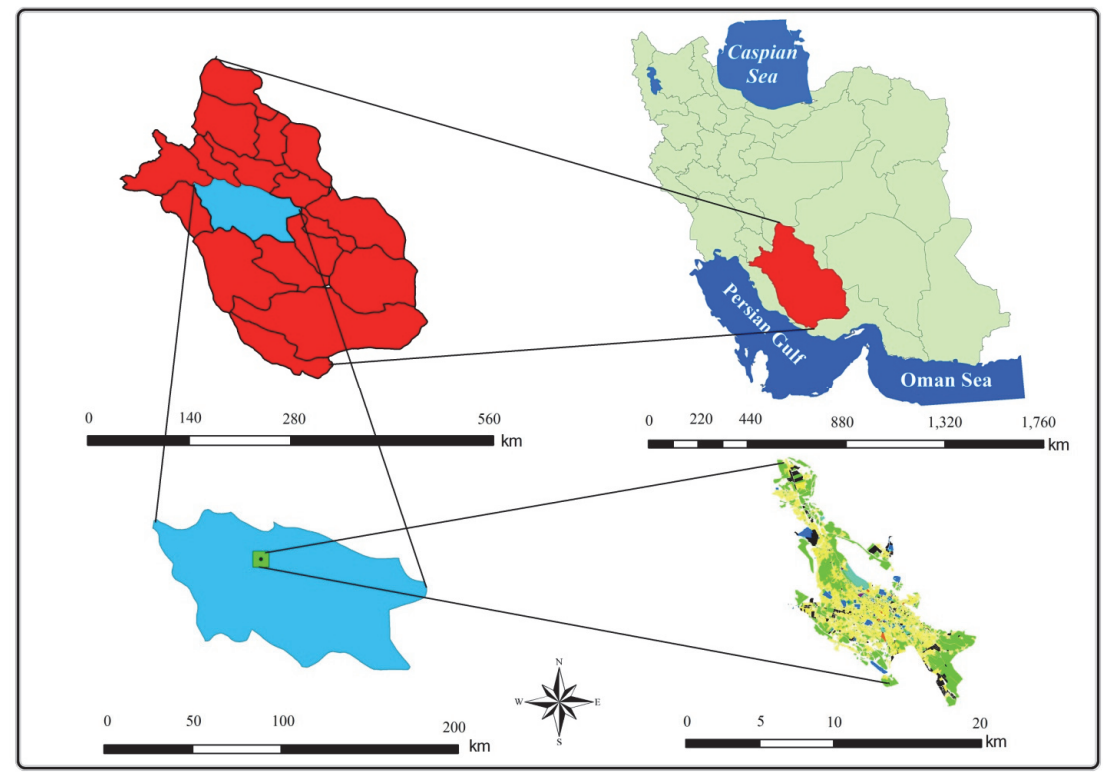

Fig. 1. Location of Shiraz City in Fars and Iran

\section{Theoretical Bases}

\subsection{Medical Tourism}

Medical tourism refers to the travel of people from overseas (often from great distances) to another country in order to obtain medical services (which are either nonexistent in terms of costs and time or not easily available) (Keckley \& Underwood, 2009). Local tourism also refers to the domestic travels of patients in search of better specialists, cheaper and more quality services (Connel, 2010a, 2010b; Kazemi, 2008). These types of travels are deliberately related to the direct intervention of medical 
matters and they are expected to have excellent and long-lasting results. This is a completely new area that satisfies the needs of many individuals whose number is increasing and they could be tourists and patients (Horowitz \& Rosensweig, 2008). Medical tourism formed in its present form in 1990s in response to issues such as increase in healthcare costs and health insurance in developed countries, long waiting lists for receiving medical services, reduction of air transport expenses, access to internet, demand for cosmetic surgery, aging of the often rich generation who proliferated after the war (a generation who had more needs and higher expectations of healthcare services), ability to pay for medical treatments, having spare time for traveling and mixing medical treatments with vacations (Keckley \& Underwood, 2009). In target countries, advances in medical technology and surgical skills, emergence of a middle class with new needs, privatization and reconstruction following economic problems caused medical tourism services to be supported. In many developing countries (countries located in South of Africa to Russia), elites of the society whose number is growing, by ridiculing local healthcare services and treatments increased the need for advancement of healthcare. The origin had little to do with health tourism and this was totally practical (Glinos et al., 2010). Medical tourism often refers to increased amount of medical services for all tourists. Traditionally people used only local healthcare services, but everything changed in the $21^{\text {st }}$ century and medical tourism annual earnings increased to 60 billion dollars and accounted for a 20-percent annual growth (Horowitz et al., 2007: 33). Medical tourism's role as one of the components of medical tourism is associated with tourism industry through hotels, travel agencies, welfare-recreational activities and all relevant infrastructures. With the development of medical tourism, this industry achieves more harmony with associated companies such as Medical Tourism Association (MTA) in U.S and other institutions including hospitals, insurance firms and newly-establish travel agencies. As part of medical industry, medical tourism is improved significantly in the post-industrial world by many governments (Connel, 2010a, 2010b). Several Asian countries including Thailand, Singapore and Malaysia have developed a 5-year plan for extending medical tourism and other form of tourism. Thai prime minister states at the close of the year 2009, Thailand's public sector is the key to sustained development for this country's economy. Thailand is now focusing on establishing the foundations of its economy in a post-crisis world. Projects like tourism projects strengthen the public sector of the country. Trips made for obtaining healthcare services are rapidly becoming growing and popular among tourists who come to Thailand. This is because of Thailand's facilities that enjoy international medical, healthcare and wellbeing standards. This is also true for high quality services, indeed with Thailand's means. Like everywhere else, medical tourism here paves the way for further growth for the country and this is after the world economic crisis. As the Thai prime minster said officially, medical tourism showcases Thailand's natural beauty and hospitality (Vejjajiva, 2009: 213). By establishing and making medical tourism known, it finds social and economic aspects.

\section{Factors Creating the Demand for Medical Tourism}

The most important factors that create demand for medical tourism are

- Lower price

In fact, one of the most important factors that cause patients choose another country for their treatment is the lower price of services. Table 1 compares some of the prices between different countries:

Table 1

Comparative prices for surgery and treatment in different countries in April 2010 (In US dollars)

\begin{tabular}{llllll}
\hline Surgery & U.S.A & Costa Rica & Singapore & Thailand & India \\
\hline CABG (heart bypass) & 152000 & 25000 & 32000 & 23000 & 8000 \\
Heart valve replacement & 180000 & 29000 & 23000 & 22000 & 12000 \\
Hip replacement & 101000 & 11000 & 16000 & 13000 & 8000 \\
Knee replacement & 66000 & 12000 & 19000 & 12500 & 7500 \\
Spinal fusion & 104000 & 16000 & 21000 & 10000 & 8000 \\
Hysterectomy (vaginal) & 32000 & 5000 & 10000 & 4000 & 3500 \\
\hline
\end{tabular}


- Search for treatment with better quality

Many Latin American, Asian and African countries do not have appropriate treatment quality because of shortage of resources and facilities, professional staff and weak infrastructures. People from these countries (especially the rich echelon) choose another country for their treatment.

- Attention to such matters as culture, language, etc.

Many failures in treatments are the direct result of inability to establish appropriate communication with the patient. Failing to establish good communication occurs as a result of differences in culture, language, literacy level and cognitive limitations.

- Easy access to information

Thanks to the internet and other technologies, people can gain significant amount of information about treatment of diseases in different countries (in terms of price, quality, etc.) and then make an informed decision about the treatment they want.

- Weak healthcare insurance

- Lack of good insurance coverage has forced many people to travel overseas to receive medical services. Even the best and most inclusive insurances do not cover cosmetic surgery, dental services and many other operations and surgeries) and therefore, increase in treatment costs for such problems paves the way for medical tourism.

- Advent of information and communication technology

The emergence of information and communication technology have helped the medical tourism industry by transferring patients' information (patients' records, teleradiology, etc.).

- Alternative medicine

Today, many people look for alternative medical methods to cure their refractory diseases (e.g. cancer and diabetes). The Chinese acupuncture and Ayurveda have become very popular nowadays.

- New treatment methods

New treatment methods such as treatment using stem cells have also contributed to medical tourism to the extent that people travel to leading countries to obtain these treatments.

- Development of air transport, hotel and telecommunication industries

Development of these industries has directed the world towards the global village and has caused people travel more comfortably than before to other places in the world.

- Privacy of patients

Exigent regulations should be established to ensure the privacy of patients. Some of the regulations laid down for these fields are Health Insurance Portability and Accountability Act in U.S, Federal Data Protection Act in Germany, Data Protection Act 1998 in UK, Personal Information Protection and Electronic Documents Act in Canada.

\section{Research Methodology and Procedures}

The dominant approach in this study is applied-developmental and research methodology is descriptive, analysis and survey. Required information was gathered by documentary, library, survey and interview methods. The statistical population of the research is composed of foreign medical tourists who had traveled to Shiraz in 2013 to do medical treatments. According to the statistics published by the Ministry of Health and Medical Education, annually more than 20 to 35 thousand tourists from the Persian Gulf region go to some of the cities in our country for treatment; statistics prove this claim that at least 70 percent of these patients enter Shiraz for 
treatment (Ministry of Health and Medical Education Statistical Center, 1393). Therefore, 17500 people were considered as the statistical population. In this research, Cochran method was used to calculate sample volume. With respect to the statistical population in this study, the sample volume calculated using Cochran formulation, is determined to be 378 foreign tourists and increased to 400 for reliability and validity purposes.

$n=\frac{\frac{t^{2} p q}{d^{2}}}{1+\frac{1}{N}\left(\frac{t^{2} p q}{d^{2}}-1\right)}=\frac{\frac{1.96^{2} * 0.5 * 0.5}{0.05^{2}}}{1+\frac{1}{17500}\left(\frac{1.96^{2} * 0.5 * 0.5}{0.05^{2}}-1\right)}=378$

$\mathrm{t}=1.96, \quad \mathrm{p}=0.5, \quad \mathrm{q}=0.5, \quad \mathrm{~d}=0.05$

$\mathrm{t}=$ significance coefficient, $\mathrm{p}=$ percentage of individuals with the desired characteristics, $\mathrm{q}=$ percentage of individuals without the desired characteristics, $\mathrm{d}=$ error, $\mathrm{n}=$ sample volume, $\mathrm{N}=$ total number of the population (Hafeznia, 2010; Harahsheh, 2002). In this research, in order to select the sample of the population of tourists, stratified sampling proportionate to size was used. Pearson linear correlation technique and one-way variance analysis were used to analyze the data and test the hypotheses. Data analysis was performed using SPSS 19.0 software.

\section{Research Findings}

\subsection{Descriptive Statistics}

Descriptive statistics associated with the characteristics of this study's sample population (population of respondents in this research) are presented in Table 2.

Table 2

Descriptive analysis of sample population characteristics

\begin{tabular}{|c|c|c|c|c|c|c|c|}
\hline \multirow{3}{*}{ Gender } & & Frequency & Percentage & \multirow{8}{*}{$\begin{array}{l}\text { Age } \\
\text { (Years) }\end{array}$} & Less than 20 & 21 & 5.3 \\
\hline & Male & 307 & 76.8 & & $20-25$ & 30 & 7.5 \\
\hline & Female & 93 & 23.3 & & $26-31$ & 49 & 12.3 \\
\hline \multirow{12}{*}{ Nationality } & Oman & 103 & 25.8 & & $32-37$ & 66 & 16.5 \\
\hline & Bahrain & 74 & 18.5 & & $38-43$ & 87 & 21.8 \\
\hline & U.A.E & 63 & 15.8 & & $44-49$ & 105 & 26.3 \\
\hline & Kuwait & 51 & 12.8 & & $50 \&$ above & 41 & 10.3 \\
\hline & Iraq & 42 & 10.5 & & Not Mentioned & 1 & 0.3 \\
\hline & Canada & 16 & 4 & \multirow{5}{*}{ Education } & Below Diploma & 18 & 4.5 \\
\hline & France & 11 & 2.8 & & Diploma & 31 & 7.8 \\
\hline & U.S & 9 & 2.3 & & Associate Degree & 38 & 9.5 \\
\hline & U.K & 7 & 1.8 & & Bachelor's & 16 & 0.5 \\
\hline & Germany & 6 & 1.5 & & Master's \&Higher & 151 & 37.8 \\
\hline & Afghanistan & 12 & 3 & \multirow{6}{*}{ Occupation } & State & 39 & 9.8 \\
\hline & Malaysia & 6 & 1.5 & & Private & 195 & 0.8 \\
\hline \multirow{4}{*}{ Marital Status } & Married & 304 & 76 & & Housewife & 56 & 14 \\
\hline & Single & 96 & 24 & & Student & 11 & 2.8 \\
\hline & & & & & Retired & 76 & 19 \\
\hline & & & & & Unemployed & 23 & 5.8 \\
\hline
\end{tabular}

\subsection{Deductive Statistics}

In this section, after identifying the main variables of the research, they are analyzed to determine which independent variables have significant relationships with which dependent variables. 


\subsection{Hypothesis Test}

\section{First Hypothesis}

In order to test the first hypothesis (the prices of medical and tourist services are related to medical tourism development in Shiraz City), Pearson's linear correlation test was used. The null hypothesis is that there is no relationship between medical tourism development in Shiraz City and the price of medical and tourist services and the opposite hypothesis indicates that a relationship exists between the two variables.

\section{Table 3}

Significant relationship test between price of medical and tourist services and medical tourism development

\begin{tabular}{lcccc}
\hline Variable & Mean & Standard Deviation & Pearson Coefficient & Significance Level \\
\hline Price of Medical and Tourist Service & 55.03 & 5.15 & -0.72 & 0.0001 \\
Medical Tourism Development & 63.05 & 4.93 & & 0.001 \\
\hline
\end{tabular}

As it can be observed from Table 3, the mean of tourist and medical service prices is 55.03 and the mean of medical tourism development is 63.05 . Pearson's coefficient measure is found to be $r=-0.72$, which is negative and inverse, i.e. increase in prices of tourist and medical services decreases medical tourism development and reverse. Considering the significance level ( $\mathrm{sig}=0.0001)$, which is lower than 0.05 , this relationship (which is strong and inverse) is corroborated with 95 percent significance; the null hypothesis, therefore, is rejected.

\section{Second Hypothesis}

In order to test the second hypothesis (the quality of medical and tourist services are related to medical tourism development in Shiraz City), Pearson's linear correlation test was used. The null hypothesis is that there is no relationship between medical tourism development in Shiraz City and the quality of medical and tourist services and the opposite hypothesis indicates that a relationship exists between the two variables.

\section{Table 4}

Significant relationship test between quality of medical and tourist services and medical tourism development

\begin{tabular}{ccccc}
\hline Variable & Mean & Standard Deviation & Pearson Coefficient & Significance Level \\
\hline Quality of Medical and Tourist Service & 98.5 & 7.02 & \multirow{2}{*}{0.64} & 0,0001 \\
Medical Tourism Development & 63.05 & 4.93 & & \\
\hline
\end{tabular}

As it can be observed from Table 4, the mean of tourist and medical service quality is 98.5 and the mean of medical tourism development is equal to 63.05. Pearson's coefficient measure is equal to $r=.64$, which is positive and direct, i.e. improvement in quality of tourist and medical services increases medical tourism development and reverse. Considering the significance level ( $\mathrm{sig}=0.0001)$, which is lower than 0.05, this relationship (which is strong and inclined to average) is corroborated with 99 percent significance; the null hypothesis, therefore, is rejected.

\section{Third Hypothesis}

In order to test the third hypothesis (culture is related to medical tourism development in Shiraz City), Pearson's linear correlation test was used. The null hypothesis is there is no relationship between medical tourism development in Shiraz City and culture and the opposite hypothesis indicates that a relationship exists between the two variables. 
Table 5

Significant Relationship Test between Culture and Medical Tourism Development

\begin{tabular}{ccccc}
\hline Variable & Mean & Standard Deviation & Pearson Coefficient & Significance Level \\
\hline Culture & 74 & 6.59 & \multirow{2}{*}{0.53} & 0.002 \\
\hline Medical Tourism Development & 63.05 & 4.93 & & \\
\hline
\end{tabular}

As it can be seen from Table 5, the mean of culture is 74 and the mean of medical tourism development is 63.05. Pearson's coefficient measure is equal to $\mathrm{r}=.53$, which is positive and direct, i.e. improvement in culture (which is associated more with hospitality and medical staff's behavior) increases medical tourism development. Considering the significance level $(\mathrm{sig}=0.0002)$ which is lower than 0.05 , this relationship (which is inclined to average) is corroborated with 95 percent significance; the null hypothesis, therefore, is unacceptable.

\section{Fourth Hypothesis}

In order to test the fourth hypothesis (medical and tourist facilities, amenities and equipment are related to medical tourism development in Shiraz City), Pearson's linear correlation test was used. The null hypothesis is that there is no relationship between medical tourism development in Shiraz City and medical and tourist facilities, amenities and equipment and the opposite hypothesis indicates that a relationship exists between the two variables.

\section{Table 6}

Significant Relationship Test between medical and tourist facilities, amenities and equipment and Medical Tourism Development

\begin{tabular}{ccccc}
\hline Variable & Mean & Standard Deviation & Pearson Coefficient & Significance Level \\
\hline $\begin{array}{c}\text { Medical and tourist facilities, } \\
\text { amenities and equipment }\end{array}$ & 111.35 & 9.07 & 0.61 & 0.0001 \\
Medical Tourism Development & 63.05 & 4.93 & & \\
\hline
\end{tabular}

According to Table 6, the mean of medical and tourist facilities, amenities and equipment is equal to 111.35 and the mean of medical tourism development is 63.05. Pearson's coefficient measure is equal to $\mathrm{r}=.61$, which is positive and direct, i.e. increasing medical and tourist facilities, amenities and equipment increases medical tourism development. Considering the significance level (sig=0.0002), which is lower than 0.05, this relationship (this relationship is in average level) is corroborated with 99 percent significance; the null hypothesis, therefore, is unacceptable.

\section{Fifth Hypothesis}

In order to test the fifth hypothesis (information and communications technology is related to medical tourism development in Shiraz City), Pearson's linear correlation test was used. The null hypothesis is that there is no relationship between medical tourism development in Shiraz City and information and communications technology and the opposite hypothesis indicates that a relationship exists between the two variables.

\section{Table 7}

Significant Relationship Test between information and communications technology and Medical Tourism Development

\begin{tabular}{lcccc}
\hline \multicolumn{1}{c}{ Variable } & Mean & Standard Deviation & Pearson Coefficient & Significance Level \\
\hline Information and communication technology & 57.75 & 5 & 0.37 & 0.027 \\
Medical Tourism Development & 63.05 & 4.93 & \multirow{2}{*}{0.37} \\
\hline
\end{tabular}

According to the results of Table 7, the mean of information and communications technology is 57.75 and the mean of medical tourism development is 63.05. Pearson's coefficient measure is equal to $r=.37$, 
which is positive and direct, i.e. increasing usage of information and communications technology increases medical tourism development. Considering the significance level (sig=0.027), which is lower than 0.05 , this relationship (this relationship is weak) is corroborated with 99 percent significance; the null hypothesis, therefore, is unacceptable. Table 8 presents the results of simultaneous multivariate regression analysis in order to determine the dependent variable of medical tourism development. In this section, the effect of dependent variables on determining the medical tourism development is shown.

\section{Table 8}

Variables inserted in Regression Equation for Determining Medical Tourism Development Variance

\begin{tabular}{|c|c|c|c|c|c|c|}
\hline Variable Name & $\mathrm{R}$ & $\mathrm{R}^{2}$ & F Value & Beta & $\mathrm{T}$ & Sig T \\
\hline Price of Tourist and Medical Services & 0.68 & 0.46 & 98.746 & -0.534 & 63.275 & 0.0001 \\
\hline Quality of Tourist and Medical Services & & & 54.382 & 0.523 & 29.783 & 0.0001 \\
\hline Culture & & & 28.873 & 0.321 & 18.152 & 0.0001 \\
\hline Medical and Tourist Facilities, Amenities and Equipment & & & 39.784 & 0.475 & 23.492 & 0.0001 \\
\hline Information and Communications Technology & & & 34.543 & 0.433 & 19.154 & 0.0001 \\
\hline
\end{tabular}

The statistical findings (Table 8) indicate that the independent variables of the price of medical and tourist services, quality of medical and tourist services, culture, medical and tourist facilities, amenities and equipment, and information and communications technology (ICT) are inserted in the equation. Based on the data provided by the table and relying on $\mathrm{R}^{2}$ values, it can be said that 46 percent of changes in dependent variable are determined directly by the above variables. As it can be observed, the above regression model has been able to describe 46 of changes in medical tourism development variables. Thus, we may claim that 54 percent of changes in the dependent variable are determined by other variables that have not been included in this study. Based on Beta coefficient of -0.594 , the variable of medical and tourist service prices is negatively and inversely associated with medical tourism development. In other words, increasing the price of medical and tourist services leads to reduced development of medical tourism. The variable of medical and tourist service quality with a Beta coefficient of 0.523 also indicates a positive and direct relationship between this variable and medical tourism development. The variable of culture with a Beta coefficient of 0.321 also shows a positive and direct relationship between this variable and medical tourism development. Furthermore, the variable of medical and tourist facilities, amenities and equipment with a Beta value of 0.475 indicates a positive and direct relationship with medical tourism development variable. Finally, the variable of information and communications technology (ICT) with a Beta value of 0.433 , points to a positive and direct relationship with the variable of medical tourism development.

\section{Fifth Hypothesis}

In order to test the fifth hypothesis (There are differences between foreign medical tourists in terms of degree of satisfaction (of prices, quality, culture, facilities, amenities and equipment, and information and communications technology), one-way variance analysis test was used. The null hypothesis is that there is no difference between the variable of foreign medical tourists and the variable of foreign tourists' satisfaction and the opposite hypothesis indicates that there was a difference between the two variables.

Table 9 shows the results of the analysis of differences between foreign medical tourists in terms of degree of satisfaction. The highest satisfaction degree was found to be among Kuwaiti medical tourists with a mean of 68.26 and the lowest degree of satisfaction was found among Afghan medical tourists with a mean of 45.12. Considering the fact that according to $F$ test, the differences observed between the means of different countries concerning satisfaction degree are significant at value of 2.022 and significance level of 95 percent ( $\mathrm{sig}=0.037$ ), the above hypothesis is thus substantiated. 
Table 9

Difference of Satisfaction Degree among Foreign Medical Tourists Test

\begin{tabular}{|c|c|c|c|c|c|c|}
\hline Degree & Frequency & Satisfaction Mean & Standard Deviation & $\mathrm{F}$ & $\mathrm{DF}$ & Significance Level \\
\hline Oman & 103 & 59.25 & 7.12 & \multirow{12}{*}{2.022} & \multirow{12}{*}{11} & \multirow{12}{*}{0.037} \\
\hline Bahrain & 74 & 62.51 & 6.75 & & & \\
\hline U.A.E & 63 & 53.12 & 9.15 & & & \\
\hline Kuwait & 51 & 68.28 & 3.26 & & & \\
\hline Iraq & 42 & 60.13 & 7.92 & & & \\
\hline Canada & 16 & 54.18 & 8.21 & & & \\
\hline France & 11 & 61.84 & 5.86 & & & \\
\hline U.S & 9 & 59.35 & 5.92 & & & \\
\hline U.K & 7 & 55.83 & 8.41 & & & \\
\hline Germany & 6 & 67.4 & 5.12 & & & \\
\hline Afghanistan & 12 & 45.12 & 11.52 & & & \\
\hline Malaysia & 6 & 63.60 & 5.42 & & & \\
\hline
\end{tabular}

\section{Discussion and conclusion}

Medical tourism is associated with the international phenomenon of an individual travelling abroad to reach healthcare services because of unavailable insurances, service usage restrictions, and insufficient access to medical services (Nasiripour \& Salmani, 2010; Runnels \& Carrera, 2012; Sadermomtaz \& Agha Rahimi, 2010; Wilson, 2011; Zia Sheikholeslami et al., 2007). Reduction of transport expenses, higher revenues, transfer of technology and knowledge and reduction of expenses as a result of competition between competing counties are all considered as primary issues, which help medical tourists travel to other countries to use medical services of these counties. With an annual revenue of well above 60 million dollars and annual growth of 60 percent, this industry is now considered in the world as one of the thriving markets of tourism. By building and making medical tourism known, it determines social and economic aspects. Economic advantages are the main issues in medical tourism due to considerable differences in treatment expenses in various countries. However, these are not the only factors affecting medical tourism. In a country where public sector medical services are dominant, the most important defect is long waiting lists and in many developed countries adequate and appropriate access to quality medical services is a determining factor. The role of medical tourism as one of the components of tourism industry is associated with tourism industry through hotels, travel agencies, welfare-recreational activities and all relevant infrastructures. As part of medical industry, medical tourism is improved substantially in the post-industrial world by many governments and many countries are currently supporting practical and legal plans for services and plan for development of this industry. Accordingly, in order to prepare for medical tourism development strategy in Shiraz City, the present study was executed with the aim of planning and developing medical tourism. Statistical analysis of Pearson's linear correlation has disclosed that Pearson coefficient degree $(\mathrm{r}=-0.72)$ for medical and tourist services was negative and inverse, which means that medical tourism development reduces with increase in tourist and medical service prices and vice versa. Considering the significance level ( $\mathrm{Sig}=0.0001$ ), which is lower than 0.05, it was known that the price of medical and tourist services influences medical tourism development in Shiraz City. The variable of tourist and medical services quality with Pearson coefficient of $r=0.64$ and significance level of Sig $=0.0001$ has effect on medical tourism development, which indicates that medical tourism development increase with quality of tourist and medical quality. The variable of culture with Pearson coefficient of $\mathrm{r}=0.53$ and significance level of 0.002 has impact on medical tourism development which means that improvement of culture, more associated with hospitality and medical centers' staffs' behavior towards patients, increases medical tourism development. The variable of medical and tourist facilities, amenities and equipment with Pearson coefficient level of $r=0.61$ and significance level sig $=0.0001$ influences on medical tourism development, which means that the level of medical tourism development increases with improvement of medical and tourist facilities, amenities and equipment. The variable of information and 
communications technology with Pearson coefficient $r=0.37$ and significance level sig $=0.027$ influence medical tourism development which means that medical tourism development level increases with increase in using information and communications technology. Results obtained from multivariate regression also affirm the influence of independent variable on the dependent variable, development of medical tourism. In addition, results obtained from variance analysis have revealed that considering the difference observed between means of different countries in terms of satisfaction degree, based on $\mathrm{F}$ test with the value of 2.022 and significance level of sig $=0.037$, there is a difference between medical tourists from various countries in terms of satisfaction (of prices, quality, culture, facilities, amenities and equipment, information and communications technology). The highest degree of satisfaction was found to be among Kuwaiti medical tourists with a mean of 68.26 and the lowest degree of satisfaction was obtained for Afghan medical tourists with a mean of 45.12 .

\section{Suggestions}

Observing that price of medical and tourist services, quality of medical and tourist services, culture, medical and tourist facilities, amenities and equipment, and information and communications technology are important factors influencing on medical tourism development in Shiraz City, in order to improve these factors, which lead to development of foreign medical tourism in Shiraz City, the following suggestions are proposed:

- Costs of tourist and medical services ought to be transparent to make it possible for patients to compare them with other countries. Since the price of tourist and medical services in Shiraz are much lower than many countries in the region, this factor can attract more medical tourists to Shiraz as long as this factor is transparent.

- Supervising price and quality of medical and tourist services provided to patients is essential since some medical tourists' complaints in this regard against medical as well as tourist service-providing centers.

- There must be some granting concessions and facilities to patients and their companions.

- It is necessary to provide accommodation in hospital campus for patients and their companions during their stays or when they are in recuperation period and providing transport facilities for patients and their companions.

- It is recommended to introduce Shiraz's medical and tourist capabilities through electronic and nonelectronic (in international medical tourism exhibitions, embassies, tour guide booklets, professional magazines, brochures, and satellite networks) advertisements.

- Customer retention, market penetration, good understanding of the target markets in the region with cultural, religious, and language commonalities and geographical vicinity are among other important tools to promote tourism.

- Employing marketing advisors, drawing contracts with medical tourism firms or establishing medical tourism companies, establishing agent offices in other countries, employing hotel agents in hospitals' board of directors may promote tourism industry.

- It is also an interesting idea to launch websites associated with medical tourism by every center in international languages. This helps patients have access to information since most medical tourists look for the internet for their needs. No medical center in Shiraz City has an official website and most medical tourists, particularly tourists from the Persian Gulf area are brought to Shiraz's medical centers through dealers. 
- It is also necessary to improve extended access to useful information networks and databases, online communication among patients and physicians and employing long-distance technologies such as telemedicine, tele-consultation, tele-learning and possibility of follow-up after treatment.

- One important issue is to integrate hospitals' information systems, upgrade, and modify techniques for data collection, registration and reporting of foreign patients' information.

- It is also essential to sign contracts with other countries, especially Islamic countries, in the field of medical and tourist cooperation and referring patients from those countries to Iran since most healthcare recipients are from the region's Islamic countries.

- Having contracts with active international insurances and providing facilities for the payment of tourist and medical services in compliance with other countries including travel checks, credit cards, wire transfer and popular currencies of the world are among other necessary steps to promote tourism industry.

- It is essential to employ people who are familiar with international languages, particularly English and Arabic, in medical centers.

- It is important to provide facilities according to the nationality and culture of patients and their companions.

- It is essential to provide facilities for easier visit of foreigners to Iran including medical visa issuance for medical tourists of other counties and resolving visa problems.

- It is important to make some efforts to attract Iranian expatriates for medical and tourist matters.

- It is important to organize tourist tours before and after the treatment of patient according to his $\backslash$ her conditions.

- It is important to extend medical visa so that the patients would not be forced to return to their home countries before the completion of treatments.

- It is essential to use advanced and modern medical facilities and equipment in compliance with world standards.

- Customs and tax reliefs for standard medical equipment imports are among other important factors.

- It is also important to employ some mechanisms to prevent emigration of skilled physicians for in recent years, many of Shiraz's distinguished physicians have migrated to other countries.

- Using overseas-based Iranian physicians with board certificate and international records, high-tier professional human resource proficient in English with strong public relations are among necessary steps to promote tourism industry.

- We also need to provide world's latest and advanced, medical techniques, especially in cosmetic surgeries such as hair transplant.

- Finally, it is necessary that the Ministry of Health and Medical Education take steps to enforce worldclass standards for hospitality services and provide necessary conditions to obtain international credentials such as Joint International Commission certification. 


\section{References}

Amodeo, J. (2010). Medical refugees and the future of health tourism. World Medical \& Health Policy, 2(4), 65-81.

Avdimiotis, S., Bonarou, C., Dermetzoupoulos, A., Karamanidis, I., Mavrodontis, T., Kelessidis, V., Kalonaki, E. (2009). TOUREG: Global SWOT Analysis. A Report Produced For Toureg Project, Deliverable D.2.1.

Angelevska-Najdeska, K., \& Rakicevik, G. (2012). Planning of sustainable tourism development. Procedia-Social and Behavioral Sciences, 44, 210-220.

Bina, M. (2007). Unaffordability Ebola. Medical Tourism, 1, 48-49.

Connel, J. (2010a). Medical tourism. University of Sydney, Australia.

Connel, J. (2010b). Migration and the globalization of health care. Cheltenham: Edward Elgar.

Delgoshaee, B., Jabbari, A.R., Farzin, M.R., Sherbafchizade, N., \& Tabibi J. (2011). The present state of medical tourism: a case study of Iran. Payesh Quarterly, 11(2), 157-165.

Faramarzi, A. (2011). Treatment tourism. http://www. System.Parsiblog.com.

Gilmore, A. (2008). Small-scale tourism development in communist Cuba. A thesis presented to the University of Waterloo in fulfillment of the thesis requirement for the degree of master of environmental studies in geography, tourism policy and planning.

Glinos, I. A., Baeten, R., \& Maarse, H. (2010). Purchasing health services abroad: practices of crossborder contracting and patient mobility in six European countries. Health Policy, 95(2), 103-112.

Hafeznia, M. (2010). Introduction to methodology in humanities, $17^{\text {th }}$ ed., Tehran: SAMT.

Harahsheh, S. S. (2002). Curative tourism in Jordan and its potential development. Bournemouth University, United Kingdom, 3(1), 45-78.

Hinnawi, R. (2007). Investment in medical tourism industry in MENA region. Medical Tourism \& Health Care Management Jordan.

Horowitz, M. D., \& Rosensweig, J. A. (2008). Medical tourism vs. traditional international medical travel: a tale of two models. International Medical Travel Journal, 3, 30-33.

Horowitz, M. D., Rosensweig, J. A., \& Jones, C. A. (2007). Medical tourism: globalization of the healthcare marketplace. Medscape General Medicine, 9(4), 33.

Jabbari, A. (2008). The Designation a pattern for medical tourism in Iran, MA thesis. Faculty of medical and treatment management. Tehran, sciences and research branch. Islamic Azad University.

Jahani, M.A. (2008). The designation of globalization pattern of hospitals services in Iran. Dissertation of Health care Management, Tehran, Science and Research Branch, Islamic Azad University.

Kalshetti, P., \& Pillai, D. (2008). Tourism products development and management medical tourism-A Shifting Paradigm, 15-17.

Kazemi, Z. (2008). Study of the effective factors for attracting medical tourism in Iran. Master's Thesis, Lulea University of Technology.

Keckley, P., \& Underwood, H. (2009). Medical tourism: Update and implications, Available at: Deloitte Center for Health Solutions http://www.deloitte.com/.

Lautier, M. (2008). Export of health services from developing countries: The case of Tunisia. Social Science \& Medicine, 67(1), 101-110.

Masoumi, M. (2008). Record of tourism planning in Iran. $1^{\text {st }}$ ed., Tehran: Samira publications.

Ministry of Health and Medical Education. (2013). Center of statistic.

Monica, H., \& Yu-Feng, H. (2006). Thailand medical tourism cluster [Online], Available from: URL: www.isc.hbs.edu/pdf/student-project/ Thailand-medical-tourism/.

Moshiri, S.R., \& Fathollahi, F. (2010). Hot springs, capabilities of Ramsar in the field of treatment tourism. Journal of Geography, 57-76.

Nagarajan, G.S. (2004). Medical Tourism In India: Strategy For Its Development Crisil Young Thought Leader Series, Dissertation, G- 216, IIM-B Hostels, Indian Institute of Management- Bangalore, 117.

Nasiripour, A.A., \& Salmani, L. (2010). The role of Tehran hospital capabilities in the improvement of treatment tourism. Hospital Quarterly, 9(3-4), 57-67. 
Runnels, V., \& Carrera, P. M. (2012). Why do patients engage in medical tourism?. Maturitas, 73(4), 300-304.

Sadermomtaz N., \& Agha Rahimi Z. (2010). Medical tourism industry in Iran: strategies for development. Journal of Health Information Management, Special issue, 516-524.

Shiraz University of Medical Sciences. (2013). Statistical Center.

Smith, R., Martínez Álvarez, M., \& Chanda, R. (2011). Medical tourism: a review of the literature and analysis of a role for bi-lateral trade. Health Policy,103(2), 276-282.

Smith, R. D., Chanda, R., \& Tangcharoensathien, V. (2009). Trade in health-related services. The Lancet, 373(9663), 593-601.

Surgery Planet. (2010). Available at: http://www.surgeryplanet.com/(accessed12 April 2010).

Vejjajiva, A. (2009). Message. Medical Tourism, 1, 4.

Williams, S. (2009). Tourism geography: a new synthesis. Routledge.

Wilson, A. (2011). Foreign bodies and national scales: Medical tourism in Thailand. Body \& Society, 17(2-3), 121-137.

Zia Sheikholeslami, N., Rezaeian, M., Behsoun, M., \& Taghavipour, M. (2007). The knowledge and attitude of doctors and nurses and student Rafsanjan university of medical sciences regarding medical tourism in 2007. Iranian Journal of Epidemiology, 5(4), 31-36.

www.eshiraz.ir 